Vittalle - Revista de Ciências da Saúde v. 30, n. 2 (2018) 80-94

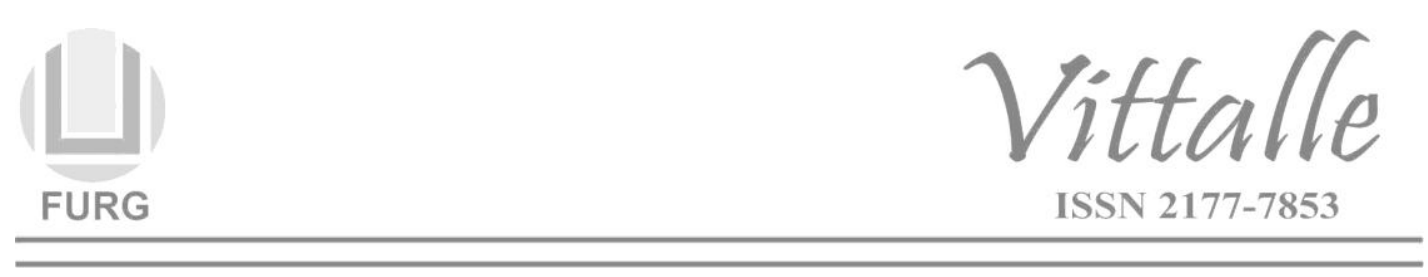

\title{
XXIV Semana Acadêmica do Curso de Medicina da Universidade Federal do Rio Grande: "vivenciando novas perspectivas, abrindo novos horizontes"
}

A XXIV Semana Acadêmica do Curso de Medicina da Universidade Federal do Rio Grande - FURG (SAMED), organizada pelo Diretório Acadêmico de Medicina Francisco Martins Bastos (DAFB), ocorreu nos dias 18, 19 e 20 de abril de 2018 e teve como público-alvo os graduandos do curso de Medicina da FURG. O evento ocorre bianualmente e em 2018 teve como Coordenadora Geral a Professora Marilice Magroski Gomes da Costa, Coordenadora Acadêmica, a Professora Vera Regina Mendonça Signorini, e Coordenador Científico, o Professor Samuel de Carvalho Dumith - todos docentes da Faculdade de Medicina da FURG.

A SAMED é um evento cuja proposta é propiciar uma oportunidade para que temas importantes e emergentes da área da saúde sejam debatidos, contribuindo para a formação de futuros profissionais atualizados tecnicamente, humanistas, críticos e reflexivos. Desse modo, no cumprimento dessa função, a SAMED propiciou aos discentes participantes: Espaço para exibição de produção científica - contando com 02 (duas) salas de apresentações de trabalhos científicos simultaneamente nos dois primeiros dias de evento; Fomento a novos questionamentos acerca do cotidiano da profissão - com a presença de palestrantes das mais diversas especialidades médicas e da área da saúde; Promoção às Ligas Acadêmicas - as quais realizaram papel organizacional tanto em palestras, como também em oficinas que visaram à atualização e o ensino teórico-prático de áreas específicas da atuação médica.

Nesta edição, a SAMED contou, também, com a colaboração do corpo discente na missão social de serem arrecadados gêneros alimentícios não perecíveis, destinados por fim à Morada das Flores - Asylo do Rio Grande.

Dessa forma, fica claro o importante papel acadêmico-científico-social que possui a SAMED, o qual nos remete ao convite para a leitura das seguintes páginas desta edição da Vittalle - Revista de Ciências da Saúde, que apresenta os Anais da XXIV Semana Acadêmica do curso de Medicina da Universidade Federal do Rio Grande.

Kevin Francisco Durigon Meneghini

(Presidente Diretório Acadêmico Francisco Martins Bastos - Gestão 2017-2018) 
ABSCESSO CEREBRAL: RELATO DE CASO

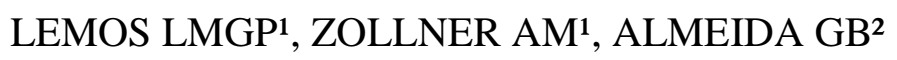

\author{
laramariagplemos@outlook.com \\ ${ }^{1}$ Graduandos de Medicina da Universidade Federal do Rio Grande, Rio Grande - RS \\ ${ }^{2}$ Docente da Faculdade de Medicina da Universidade Federal do Rio Grande, Rio Grande - RS
}

P.C.A.L., masculino, 42 anos, apresentava cefaleia holocraniana desde dezembro de 2017, em caráter compressivo, intensidade 5/10, com alívio por anti-inflamatórios. Em 21/01/2018, sofreu episódio de convulsão tônico-clônica generalizada, com relaxamento de esfíncteres e mordedura da língua, na ocasião de uma viagem a trabalho e foi levado ao hospital local em Joinville-SC. Paciente relata histórico de sinusopatia de repetição, nega antecedentes de epilepsia ou uso de medicações e possui todas as sorologias negativas. A Tomografia Computadorizada de Crânio constatou lesão ovalada em região cortical frontal direita, com edema perilesional e realce em contraste, sugestiva de abscesso cerebral. Foi iniciado tratamento com Dexametasona e Fenitoína. A investigação com tomografia não mostrou presença de infecções em possíveis sítios primários como tórax ou abdome; e a biópsia excisional de lesão dermatológica suspeita em dorso não revelou particularidades. Realizou-se um Ecocardiograma que constatou imagem em átrio direito de etiologia não esclarecida. Em 05/02/18, foi transferido para o Hospital Universitário de Rio Grande e encaminhado para a UTI, devido agitação motora, mioclonias, rebaixamento do sensório (GSC 9), hemiparesia à esquerda e disfasia. A Ressonância Nuclear Magnética de Crânio revelou lesão intra-axial cística não hemorrágica em lobo frontal direito, confirmando a hipótese de abscesso cerebral. Foi acrescentado Manitol à terapêutica inicial, assim como terapia antimicrobiana com Ceftriaxona, Metronidazol e Vancomicina para cobertura dos principais agentes etiológicos. Foi realizada drenagem do abscesso por neurocirurgião no dia 14/02/2018. Por conseguinte, houve melhora progressiva dos sintomas do paciente, sendo transferido para a enfermaria após 2 dias. O laudo anatomopatológico confirmou a hipótese diagnóstica de abscesso, sem presença de agente etiológico. No quinto dia pósdrenagem, o paciente apresentou febre vespertina e noturna. A hemocultura foi negativa. Traçaram-se hipóteses para Trombose Venosa Profunda e possível parefeito da Vancomicina. Contudo, não houve remissão da febre com $o$ fim da antibioticoterapia. Fora investigada e diagnosticada, então, TVP por trombofilia, devido à presença do fator $\mathrm{V}$ de Leiden. A ecografia transesofágica (04/03) mostrou shunt cardíaco por forame oval patente, assim como trombo aderido em átrio direito. Paciente recebeu alta hospitalar em 15/03/2018 com quadro trombofílico estabilizado, remissão total do abscesso cerebral e sem sequelas neurológicas. A etiologia do abscesso segue não esclarecida, porém há possível relação tanto com o shunt cardíaco e quadro trombofílico, quanto com o histórico de sinuspoatia de repetição.

Descritores: Abscesso; Neurologia; Infecção; Sinusite; Trombofilia. 


\title{
ALIMENTAÇÃO, OBESIDADE E QUALIDADE DE VIDA EM PROFESSORES UNIVERSITÁRIOS
}

\author{
PETTINE LJ ${ }^{1}$, DUMITH SC ${ }^{2}$ \\ luanapettine@gmail.com \\ ${ }^{1}$ Graduanda de Medicina da Universidade Federal do Rio Grande, Rio Grande - RS \\ ${ }^{2}$ Universidade Federal do Rio Grande; Programa de Pós-Graduação em Saúde Pública (PPGSP) da Universidade \\ Federal do Rio Grande, Rio Grande - RS
}

Introdução: $O$ excesso de peso e hábitos alimentares inadequados estão entre os principais fatores de risco para doenças crônicas não transmissíveis. Os professores, como grande parte da população, passaram a ter obstáculos para a prática de uma vida saudável devido à sua elevada carga laboral. Assim, é importante analisar o impacto desse comportamento na qualidade de vida dos docentes. Objetivo: Analisar a associação do excesso de peso, do baixo consumo de frutas e do consumo de refrigerantes com a qualidade de vida dos professores da Universidade Federal do Rio Grande (FURG), RS. Metodologia: Estudo observacional, transversal, abordagem quantitativa. Aprovado pelo CEPAS da FURG sob número 72/2015. Todos os professores da FURG, em atividade nos campi de Rio Grande, no segundo semestre de 2015, fizeram parte da população-alvo. Os dados foram coletados entre outubro e novembro de 2015, a partir de questionário gerado pelo Google Docs. Qualidade de vida foi analisada pelo The Medical OutcomesStudy 36- item Short Form Health Survey $(S F-36)$ e demais variáveis por um questionário semiestruturado. Análise estatística: foi usada análise de variância para cruzamento das variáveis. Resultados: A amostra contou com 270 professores, sendo a maior parte do sexo feminino, acima de 40 anos e casados. Tiveram IMC acima do normal 48,2\% dos professores, 37,0\% consumiam frutas diariamente, $60,7 \%$ consumiam refrigerante ao menos uma vez por semana. Docentes que não consumiam refrigerante regularmente apresentaram maior escore de qualidade de vida em alguns domínios do SF36. Docentes com IMC normal tiveram maiores escores de qualidade de vida no domínio de capacidade funcional. Quanto maior o IMC, menores foram os escores em "estado geral de saúde" $(p=0,03)$. No domínio emocional, foi encontrado maior escore de qualidade de vida para os professores obesos $(\mathrm{p}=0,04)$. Professores que consumiam frutas diariamente tiveram maior escore nos seguintes domínios: aspectos sociais, estado geral de saúde, vitalidade, saúde mental e dor. Considerações finais: Encontrou-se associação significativa entre excesso de peso, consumo alimentar e qualidade de vida entre professores universitários. Com este estudo, conclui-se que o consumo de refrigerantes, o baixo consumo de frutas e o excesso de peso repercutem negativamente sobre a qualidade de vida dos indivíduos. Logo, intervenções para melhorar a alimentação dos docentes e promover hábitos saudáveis são necessárias.

Descritores: Qualidade de vida; Sobrepeso; Obesidade; Frutas; Refrigerantes. 


\title{
ANÁLISE BACTERIOLÓGICA DA ÁGUA CONSUMIDA NO HU/FURG 2012- 2017
}

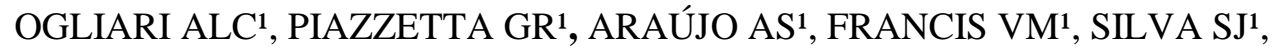 \\ BALLESTER T², GIOIA CAC ${ }^{3}$. \\ analuisa_canovaogliari@hotmail.com \\ ${ }^{1}$ Graduandos de Medicina da Universidade Federal do Rio Grande, Rio Grande - RS \\ ${ }^{2}$ Técnica do laboratório de Imunologia da Faculdade de Medicina da Universidade Federal do Rio Grande, Rio \\ Grande - RS \\ ${ }^{3}$ Professora Doutora da Faculdade de Medicina da Universidade Federal do Rio Grande, Rio Grande - RS
}

Introdução: A água é essencial para a fisiologia humana. A portaria 2914/2011 do Ministério da Saúde regulamenta os procedimentos de controle e vigilância da qualidade da água. Visando adequação a essa portaria, o setor de Microbiologia e Imunologia da Faculdade de Medicina da Universidade Federal do Rio Grande (FAMED/FURG), convidado pela Comissão de Controle de Infecção Hospitalar (CCIH) do Hospital Universitário Miguel Riet Corrêa Júnior (HU/FURG), passou a ser responsável pela análise bacteriológica da água consumida nesse hospital a partir de 2007. Objetivo: Este trabalho objetiva apresentar os dados coletados no período de fevereiro de 2012 a fevereiro de 2017. Metodologia: A análise da potabilidade da água é feita pelo método de Fermentação de Tubos Múltiplos. São coletadas amostras de cinco pontos aleatórios do hospital, semeadas em tubos contendo meio de cultivo para coliformes e incubadas a $37^{\circ} \mathrm{C}$ durante 48 horas. A positividade ocorre se houver mudança da coloração, indicando a fermentação da lactose por coliformes. Todo ponto em que houver positividade de amostra é novamente testado e, caso permaneça contaminado, é indicada sua interdição para investigação. Ao final de cinco semanas de análise, um relatório é enviado para a $\mathrm{CCIH}$. Resultados: Entre fevereiro de 2012 e fevereiro de 2017, foram analisadas cerca de 6.500 amostras de água, compondo 26 relatórios. Em cinco, constavam amostras positivas para Coliformes totais. Observou-se que, após efetuadas medidas no local de coleta, como troca de filtro, da mangueira ou autoclave da torneira, todos as respectivas amostras seguintes tornaramse negativas, sugerindo que a contaminação estava localizada no artefato de saída de água e não nas caixas d'água ou encanamentos. Considerações finais: A análise bacteriológica da água é fundamental para a prevenção de infecções relacionadas ao consumo de água não potável. No período analisado, observou-se que os pontos com amostras positivas foram rapidamente interditados até que a fonte de contaminação fosse esclarecida, evitando seu consumo. Concluise que a continuação deste trabalho é de suma importância, pois promove uma valiosa troca entra a Universidade, a comunidade hospitalar e os acadêmicos.

Descritores: Qualidade da água; Análise bacteriológica; Coliformes. 


\title{
CAMPANHA NACIONAL DO AVC: UM RELATO DE EXPERIÊNCIA
}

\author{
ROSSI LC ${ }^{1}$, MORGAN HL ${ }^{1}$, FERREIRA JN¹ ${ }^{1}$ ALMEIDA F². \\ luanacignachirossi@gmail.com \\ ${ }^{1}$ Graduandos de Medicina da Universidade Federal do Rio Grande, Rio Grande - RS \\ ${ }^{2}$ Docente da Faculdade de Medicina da Universidade Federal do Rio Grande, Rio Grande - RS
}

Introdução: No dia 29 de outubro de 2017, ocorreu a Campanha Nacional do AVC. Baseada em estatísticas alarmantes, a Liga de Neurologia da FURG decidiu engajar-se nessa campanha. Em parceria com a Rede Brasil AVC, realizou-se uma atividade em um shopping da cidade de Rio Grande para conscientização sobre prevenção e avaliação do risco de AVC nos próximos anos entre os indivíduos participantes. Objetivo: Oferecer à população da cidade de Rio Grande informações acerca dos fatores de risco, medidas preventivas e reconhecimento de um episódio de AVC. Metodologia: Durante a ação, realizou-se um estudo transversal para avaliar o risco de AVC entre os indivíduos participantes. Para coleta de dados e cálculo do risco, utilizou-se o aplicativo Stroke Riscometer (ISBN 978-0-473-30345-7), o qual permite estimar o risco absoluto de AVC nos próximos 5 e 10 anos. A coleta de dados foi realizada pelos alunos, com transcrição em fichas padronizadas e posterior digitação no programa Excel 2010 e geração de tabelas. Resultados: Foram entrevistadas 107 pessoas, das quais 63\% eram mulheres, de menos de 40 anos (52\%) e de origem caucasiana (80\%). Quanto ao peso, $36,4 \%$ encontravam-se no peso ideal (IMC 18-24,9), 42,1\% apresentavam sobrepeso (IMC 25-29,9), 15,9\% eram obesos grau I (IMC 30-34,9) e 5,6\% apresentavam obesidade severa ou mórbida (IMC > 35). Histórico familiar de AVC foi relatado por $23,3 \%$ dos indivíduos e 19,6\% eram hipertensos em tratamento, enquanto 4,7\% relataram DM2 e somente 3,7\% tiveram AVC prévio. O risco de sofrer um AVC em 5 anos foi entre $0-0,9 \%$ para $44,9 \%$ dos participantes, entre $1-1,9 \%$ para $28 \%$, entre 2 $4,9 \%$ para $16,8 \%$ e somente $3,8 \%$ tiveram risco maior de $10 \%$. Já em relação ao risco de sofrer um AVC em 10 anos, 25,2\% tiveram risco até $0,9 \%, 26,2 \%$ tiveram risco entre 1$1,9 \%, 25,2 \%$ tiveram risco entre $2-4,9 \%, 11,2 \%$ tiveram risco entre 5-9,9\%, 8,4\% tiveram risco entre $10-19,9 \%$ e $3,8 \%$ tiveram risco maior do que $20 \%$. Considerações finais: A população entrevistada apresentou baixo risco de sofrer um AVC nos próximos anos, confirmando que a ação atingiu seu público alvo: indivíduos de baixo risco visando a prevenção primária. Visto que os acidentes vasculares cerebrais são grande causa de morbimortalidade mundial e doenças potencialmente evitáveis, a prevenção torna-se imprescindível e ações como essa devem ser estimuladas.

Descritores: AVC; Campanha; Prevenção. 


\title{
CONSULTORIAS GENÉTICAS EM HOSPITAL UNIVERSITÁRIO DO RIO GRANDE DO SUL
}

\author{
MORGAN HL ${ }^{1}$, PINGUELLO EC ${ }^{1}$, KARAM SM ${ }^{2}$ \\ henrimorgan@hotmail.com \\ ${ }^{1}$ Graduandos de Medicina da Universidade Federal do Rio Grande, Rio Grande - RS \\ ${ }^{2}$ Docente da Faculdade de Medicina da Universidade Federal do Rio Grande, Rio Grande - RS
}

Introdução: A cada ano, aproximadamente 3.400 consultorias hospitalares são realizadas por geneticistas no Brasil, as quais se caracterizam por um procedimento que fornece informação e suporte para pessoas que possuem, ou tem risco para desenvolver doenças genéticas. Objetivo: Este estudo objetiva descrever o padrão das solicitações de consultoria pelos profissionais não geneticistas do Hospital Universitário da Universidade Federal do Rio Grande (FURG) e os principais diagnósticos inferidos a partir dessas avaliações. Metodologia: Foi realizada revisão dos prontuários das Consultorias de Genética Médica realizadas no HU-FURG nos períodos de janeiro de 2006 a dezembro de 2010 e de janeiro de 2014 a dezembro de 2017. A coleta dos dados foi realizada com uma ficha padronizada, com posterior digitação dos dados no programa Excel. Resultados: Dos 79 indivíduos avaliados, 63,3\% eram do sexo masculino e 50,6\% estavam na faixa etária de 0 a 7 dias de vida no momento da consultoria. Das consultorias genéticas avaliadas, $89,84 \%$ foram solicitadas por unidades pediátricas. Os principais motivos para solicitação de consultoria genética foram a presença de dismorfismos $(40,5 \%)$, aparência sindrômica $(13,9 \%)$ e distúrbios osteomusculares $(11,4 \%)$. Em 31,6\% dos casos não foi necessária a solicitação de exames complementares. O diagnóstico de doença não genética ocorreu em 29,1\% dos casos. Das doenças genéticas diagnosticadas, as mais frequentes foram as cromossômicas $(17,7 \%)$, as mendelianas $(13,9 \%)$ e as multifatoriais $(8,9 \%)$. A maioria dos casos avaliados em consultorias recebram um diagnóstico $(78,5 \%)$, sendo que dos 21 casos inconclusivos, 17 mantiveram vínculo com o serviço, permanecendo em investigação. Considerações finais: Assim, as consultorias em genética médica no HUFURG se mostraram um mecanismo muito importante para médicos e demais profissionais de saúde, aumentando a precisão dos diagnósticos e acelerando o processo da admissão até instituição da terapêutica, principalmente para os pediatras, para quem a solicitação desse procedimento parece estar incorporada à rotina de trabalho. Todos os pacientes avaliados, e/ou familiares, receberam aconselhamento genético e os que obtiveram diagnóstico de origem genética continuaram em seguimento ambulatorial ou foram encaminhados para centros de referência, como o Hospital de Clínicas de Porto Alegre.

Descritores: Consultoria; Anomalias Congênitas; Genética Médica. 


\title{
DEPRESSÃO E ANSIEDADE EM PRISIONEIROS DO EXTREMO SUL DO BRASIL
}

\author{
TÍMBOLA VS ${ }^{1}$, COSTA CR $^{1}$, FERNANDES NR ${ }^{1}$, LAZZARI TR ${ }^{1}$, GONÇALVES \\ $\mathrm{CV}^{2}$
}

\author{
viniciustimbola@hotmail.com \\ ${ }^{1}$ Graduandos de Medicina da Universidade Federal do Rio Grande, Rio Grande - RS \\ ${ }^{2}$ Docente da Faculdade de Medicina da Universidade Federal do Rio Grande, Rio Grande - RS
}

Introdução: O Brasil tem a terceira maior população carcerária do mundo, com cerca de 726 mil presos. Estudos apontam uma alta prevalência de transtornos mentais nessa população, variando de $25 \%$ a $80 \%$. Além disso, os presidiários apresentam prevalência de transtornos mentais maiores do que a população em geral (10,3\% depressão e 9,3\% ansiedade) e a presença desses se relaciona com maior reincidência de crimes. Objetivo: Identificar a prevalência e os fatores associados a transtornos mentais na população carcerária do extremo sul do Brasil. Metodologia: $O$ estudo investiga prevalência e fatores associados a transtornos mentais na população carcerária. Para isso, foram entrevistados 643 apenados do regime fechado dos presídios da $5^{\text {a }}$ Delegacia Penitenciária Regional Sul. Para avaliar transtornos mentais, foi utilizado o Mini International Neuropsychiatric Interview (MINI plus). Para avaliar fatores associados, foi aplicado questionário com variáveis socioeconômicas, prisionais, saúde mental e uso de substâncias. As variáveis foram analisadas por modelo de regressão de Poisson e as análises estatísticas foram realizadas através do software Stata ${ }^{\circledR}$ 14.0. Resultados: Das 643 pessoas entrevistadas na pesquisa, 90,2\% eram homens. Sobre a saúde mental, as prevalências encontradas para depressão e ansiedade, dentre os homens, foram 18,4\% e $17,6 \%$ respectivamente. Dentre as mulheres, a prevalência foi igual em ambos os transtornos: 41,3\%. Na amostra, 9,6\% relataram histórico de doença mental e 18,2\% disseram ter familiar com histórico de doença mental. Os fumantes foram 60,3\% e $76,2 \%$ e afirmaram já ter usado drogas. Foram identificados como fatores associados à depressão: ser do sexo feminino, histórico de doença mental, histórico de doença mental na família, não receber visitas, fumar, uso de drogas e não realizar atividades físicas no presídio. Foram identificados como fatores associados à ansiedade: ser do sexo feminino, histórico de doença mental, histórico de doença mental na família, fumar e não praticar atividades físicas no presídio. Considerações finais: $O$ estudo apontou prevalência elevada de transtornos mentais nos presos quando comparados à população em geral, principalmente nas mulheres. Além disso, destacou fatores associados com ocorrência de depressão e ansiedade. Com esses resultados, poderão ser planejadas ações com o objetivo de minimizar fatores agravantes ou desencadeantes do adoecimento mental nessa população.

Descritores: Prisioneiros; Transtornos mentais; Depressão; Ansiedade. 


\title{
DESCRIÇÃO DE DEFEITOS CONGÊNITOS NA UTI NEONATAL DO HU-FURG
}

\author{
PINGUELLO EC ${ }^{1}$, MORGAN HL ${ }^{1}$, MOURA FM', CAVOLE TR ${ }^{1}$, COSTA MMG ${ }^{1}$, \\ COSTA MP ${ }^{1}$, KARAM SM ${ }^{2}$ \\ dudaceciilia@gmail.com \\ ${ }^{1}$ Graduandos de Medicina da Universidade Federal do Rio Grande, Rio Grande - RS \\ 2Docente da Faculdade de Medicina da Universidade Federal do Rio Grande, Rio Grande - RS
}

Introdução: Defeitos congênitos são anomalias morfológicas ou funcionais presentes ao nascimento. Objetivo: Este trabalho objetiva relatar os defeitos congênitos mais frequentes e descrever a população por eles afetada na Unidade de Terapia Intensiva Neonatal (UTI) do Hospital Universitário Dr. Miguel Riet Corrêa Jr (HU-FURG), no município de Rio Grande, entre Janeiro de 2006 e Março de 2011. Metodologia: Realizou-se um estudo transversal através da revisão de prontuários dos pacientes internados na UTI neonatal no período, sendo a coleta de dados realizada por meio de fichas padronizadas com posterior digitação dos dados no programa Microsoft Excel 2010. Resultados: Foram incluídos no estudo 59 casos suspeitos de doenças genéticas segundo o capítulo XVII do Código Internacional de Doenças (malformações congênitas, deformidades e anomalias cromossômicas), representando 8,5\% do total de pacientes internados na unidade no período estudado, sendo mais frequente pacientes do sexo masculino $(57,6 \%)$, a termos $(59,3 \%)$ e com idade entre 0 e 7 dias $(81,4 \%)$. Os defeitos congênitos mais frequentes foram os Multifatoriais, sendo os mais comuns Gastrointestinais $(32,2 \%)$ e Cardíacos $(28,8 \%)$. A Síndrome de Down foi a síndrome genética reconhecível mais frequente $(11,9 \%)$ e representa os casos em que se foi possível estabelecer um diagnóstico conclusivo através de exames citogenéticos. Considerações finais: Apesar de raros isoladamente, os defeitos congênitos, em conjunto, representam grande parcela das patologias do período neonatal, demonstrando a importância dessas alterações para essa população e justificando a necessidade das avaliações pelo Médico Geneticista na UTI Neonatal.

Descritores: Anomalias Congênitas; Genética Médica; Unidade de Terapia Intensiva Neonatal. 


\title{
DOR CRÔNICA NAS COSTAS EM ADULTOS E IDOSOS: INQUÉRITO EPIDEMIOLÓGICO
}

\author{
ALMEIDA LMS ${ }^{1}$, DUMITH SC ${ }^{2}$ \\ leticiamsalmeida@hotmail.com \\ ${ }^{1}$ Graduanda de Medicina da Universidade Federal do Rio Grande, Rio Grande - RS \\ ${ }^{2}$ Universidade Federal de Rio Grande - Programa de Pós-Graduação em Saúde Pública (PPGSP) \\ da Universidade Federal de Rio Grande, Rio Grande - RS
}

Introdução: A dor nas costas é uma condição que atinge grande parte da população do país e do mundo, sendo importante causa de redução de qualidade de vida e do sono, redução no rendimento laboral, além da grande demanda aos serviços de saúde. Em um estudo de base populacional no sul do país, os autores apontaram que mais da metade da população adulta e idosa apresentou dor nas costas pelo menos uma vez no ano anterior à pesquisa. Objetivo: Esta pesquisa teve como objetivo investigar a prevalência de dor crônica nas costas e possíveis fatores associados na população adulta e idosa de um município do extremo sul do Brasil. Metodologia: Trata-se de estudo transversal, de base populacional, conduzido na cidade do Rio Grande, Rio Grande do Sul, em 2016, com indivíduos de idade igual ou maior a 18 anos. É parte constituinte de um projeto maior, intitulado "Saúde da População Rio-grandina". A coleta de dados ocorreu por meio de entrevistas domiciliares. A dor crônica nas costas foi definida como dor por mais de três meses consecutivos. Análise estatística: Para análise bruta e ajustada, utilizou-se regressão de Poisson, com ajuste robusto para variância, levando-se em consideração o efeito de delineamento amostral. As medidas apresentadas foram a razão de prevalência e o intervalo de confiança de 95\% (IC95\%), juntamente ao valor p. Resultados: A amostra foi composta por 1.300 participantes. Encontrou-se prevalência de dor crônica nas costas, no último ano, de 20,6\% (IC95\% 18,3-23,0). Essa prevalência foi maior para o sexo feminino (26,0\%), para os indivíduos com 60 anos ou mais $(24,8 \%)$, para aqueles com obesidade $(28,9 \%)$, para os fumantes $(26,9 \%)$, com maior nível de estresse $(33,3 \%)$, que dormiam menos de 6 horas por dia $(32,5 \%)$, que tinham artrite ou reumatismo $(46,5 \%)$ e que tiveram alguma fratura durante a vida $(24,8 \%)$. Considerações finais: Verificou-se que um em cada cinco indivíduos apresentou dor crônica nas costas e que os grupos de risco foram compostos por: mulheres, idosos, obesos, tabagistas, indivíduos mais estressados, que dormiam pouco, que eram portadores de artrite ou reumatismo e que já haviam sofrido fratura.

Descritores: Dor nas costas; Saúde pública; Epidemiologia. 


\title{
NÍVEL DE ATIVIDADE FÍSICA E PERCEPÇ̃̃O DO ESTILO DE VIDA DE PACIENTES PRÉ-CIRURGIA BARIÁTRICA
}

\author{
ALEXANDRINO EG ${ }^{1}$, BERTOLINI SMMG $^{2}$ \\ eduardogauze@hotmail.com \\ ${ }^{1}$ Graduando em Medicina na Universidade Federal do Rio Grande, Rio Grande - RS; \\ Mestrado em Promoção da Saúde na UNICESUMAR (Bolsa CAPES), Maringá, Paraná - PR \\ 2Doutora em Ciência Morfofuncionais na Universidade de São Paulo; \\ Professora Associada da Universidade Estadual de Maringá. \\ Coordenadora do Programa de Pós-graduação em Promoção da Saúde na UNICESUMAR, Maringá, Paraná - RS
}

Introdução: A obesidade mórbida é um estado grave e potencialmente mortal devido à associação com as outras doenças. Quando os métodos convencionais de tratamento são insuficientes, a cirurgia bariátrica é indicada. Assim, para que o paciente seja considerado apto para esse procedimento pelo Sistema Único de Saúde (SUS), é necessário que ele demonstre condições para adotar um estilo de vida adequado, posterior à intervenção cirúrgica. Objetivo: Identificar as características sociodemográficas, percepção do estilo de vida e o nível de atividade física dos pacientes obesos pré-cirurgia bariátrica. Metodologia: Pesquisa quantitativa-transversal com amostra composta por 96 pacientes obesos mórbidos pré-cirurgia bariátrica, sendo 84 mulheres e 12 homens, de Paranavaí-PR. Utilizou-se questionário para conhecimento das características sociodemográficas, Questionário Estilo de Vida Fantástico e o Questionário Internacional de Atividade Física (IPAQ-curto). Resultados: Média de idade dos pacientes de 40,3 $\pm 11,45$ anos. O maior porcentagem era casado $(45,8 \%)$, morava acompanhado $(88,5 \%)$, era ativo ocupacionalmente $(67,7 \%)$, recebia entre 2 e 3 salários mínimos $(52,1 \%)$ e tinha Ensino Médio ou Superior incompleto (38,5\%). O nível inadequado de atividade física foi de $47,8 \%$, e o domínio atividade física do questionário estilo de vida foi inadequado $(79,2 \%)$. Foram encontradas diferenças estatisticamente significantes entre o tempo de prática de atividade física semanal dos praticantes e não praticantes na adolescência $(\mathrm{p}=0,046)$. Foram observadas diferenças em relação à frequência de atividade física dos pacientes que apresentavam doenças crônicas $(\mathrm{p}=0,007)$, eram ativos ocupacionalmente $(\mathrm{p}=0,018)$ e moravam sozinhos ou acompanhados $(\mathrm{p}=0,026)$. O estilo de vida foi considerado adequado em apenas $30,2 \%$ dos pacientes. Os maiores percentuais de inadequação foram encontrados nos domínios nutrição $(100 \%)$ e atividade física $(79,2 \%)$. Verificou-se associação estatisticamente significativa entre a classificação adequada do estilo de vida e o nível de atividade física $(\mathrm{p}=0,010)$. Considerações finais: A maioria dos pacientes obesos pré-cirurgia bariátrica apresenta uma percepção de estilo de vida inadequada, apesar de terem sido considerados aptos à cirurgia bariátrica. A prática da atividade física e a nutrição são os domínios de maior impacto no estilo de vida desses pacientes e a realização de atividades físicas na adolescência pode contribuir para a adoção de um comportamento ativo quando adulto.

Descritores: Atividade Motora; Estilo de Vida; Obesidade. 


\title{
PROJETO DE EXTENSÃO PILOTO: PALESTRAS EDUCATIVAS SOBRE SÍFILIS CIDADE DE RIO GRANDE/RS/ 2017
}

\author{
ZOLLNER AM ${ }^{1}$, OGLIARI ALC $^{1}$, GIOIA CAC ${ }^{2}$. \\ anamzollner@gmail.com \\ ${ }^{1}$ Graduandos de Medicina da Universidade Federal do Rio Grande, Rio Grande - RS \\ ${ }^{2}$ Professora Doutora da Faculdade de Medicina da Universidade Federal do Rio Grande, Rio Grande - RS
}

Introdução: Apesar de crescentes esforços para controle e prevenção, a sífilis, doença causada pela bactéria Treponema pallidum, transmitida por relação sexual, contato com secreções infectadas e via transplacentária permanece presente e ativa na população, sendo crescente o número de casos no Brasil. Em Rio Grande/RS, onde a Vigilância Epidemiológica dispõe de notificações de casos da doença, notou-se uma elevação dos casos de sífilis adquirida em gestantes, e sífilis congênita no período de 2012 a 2016. Objetivo: Atualmente, Rio Grande vive uma epidemia de Sífilis. Há fatores agravantes para a disseminação da doença como o difícil acesso ao pré-natal nas Unidades Básicas de Saúde, as subnotificações da doença, falhas no diagnóstico e tratamento, bem como a falta de conhecimento sobre Infecções Sexualmente Transmissíveis (IST) por grande parte da população. Pensando na educação como instrumento de transformação a médio e longo prazo desse panorama desfavorável, em 2017, foi criado, no curso de medicina da FURG/FAMED, em parceria com a Prefeitura de Rio Grande/RS, um projeto de extensão "piloto" para divulgar conhecimentos de sífilis na comunidade. Metodologia: Inicialmente, discentes voluntários, após cursarem a disciplina de Agentes InfectoParasitários e Imunologia, foram capacitados por professores e criaram, em conjunto, diversas palestras compostas por material áudiovisual educativo (multimídia) com textos e imagens referentes à doença, adaptadas para diferentes faixas etárias. Em seguida, foram contactadas as direções das escolas de Rio Grande (zona rural e urbana), oferecendo-se a divulgação do conhecimento através de palestras. Resultados: Houve boa adesão das escolas, que receberam a proposta de intervenção, garantindo continuidade ao projeto que atuou ministrando múltiplas palestras para alunos do Ensino Fundamental, Médio e turmas noturnas de jovens e adultos no decorrer do ciclo letivo de 2017. Após cada explanação, foi aberta uma sessão para perguntas e respostas de forma a se criar um debate entre ouvintes e palestrantes a fim de se sanarem todas as possíveis dúvidas sobre a Sífilis e outras IST's. Considerações finais: Impulsionado pelo sucesso do ano anterior, o projeto ganhou continuidade no ano de 2018, ampliando seu alcance e também suas propostas de forma a abranger não somente a área de extensão mas também o ramo da pesquisa.

Descritores: Sífilis; Escolas; Palestras. 


\title{
RELATO DE CASO: "BIPOLARIDADE, DOUTOR? O SENHOR NÃO SABE NADA!"
}

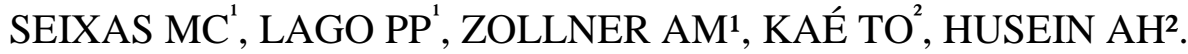 \\ marcelocseixas@hotmail.com \\ ${ }^{1}$ Graduandos de Medicina da Universidade Federal do Rio Grande, Rio Grande - RS \\ ${ }^{2}$ Associação de Caridade Santa Casa do Rio Grande, Rio Grande - RS
}

Introdução: Segundo o DSM-5, para se fechar diagnóstico de transtorno bipolar do tipo I, é necessário que o paciente apresente ao menos um episódio maníaco na vida. Esse é caracterizado como um período de humor anormalmente elevado, expansivo ou irritável e aumento persistente da energia, com duração mínima de uma semana e presente na maior parte do dia. Objetivo: Este trabalho objetiva discutir a caracterização nosológica do transtorno bipolar, bem como destacar a importância da adesão ao tratamento para garantir sua eficácia, através de um relato de caso. Metodologia: Relatamos o caso de Elisa, 23 anos, natural e procedente de São Lourenço do Sul, que foi trazida ao Hospital Psiquiátrico da Santa Casa do Rio Grande por grande agitação psicomotora, cinco dias após receber alta da mesma instituição antes do previsto a pedido de sua mãe. Resultados: Na chegada, a paciente encontrava-se agitada, hostil e com o rosto borrado de batom vermelho. Apresentava, também, delírios religiosos de conteúdo espírita. Fazia uso habitual de maconha e cocaína. Seus familiares referiam que sempre foi despojada e falante, mas que, há quatro meses, essas características estavam acentuadas e estava dormindo menos. Elisa foi internada e permaneceu por 29 dias, com diagnóstico de transtorno bipolar com episódio maníaco e sintomas psicóticos. Inicialmente, esteve em uso de risperidona, lítio, clonazepam e levomepromazina. Ao longo da internação, passou a se apresentar eutímica, com pensamento e conduta organizados e crítica de sua patologia. Recebeu alta hospitalar com suspensão do clonazepam e manutenção dos demais medicamentos, além de acompanhamento ambulatorial para garantir a continuidade do tratamento e o afastamento dos fatores estressores. Considerações finais: Com esse relato, destacamos a relevância do ajuste medicamentoso após a cessação do episódio maníaco no paciente bipolar para reduzir efeitos adversos e dependência a benzodiazepínicos. Concluímos, ressaltando a necessidade de seguimento adequado à terapêutica instituída para que sejam evitados novos surtos, tanto por parte do paciente quanto de seus familiares.

Descritores: Transtorno bipolar; Mania; Adesão ao tratamento. 


\title{
SÍNDROME DE GUILLAIN-BARRÉ: ATENÇÃO MÉDICA PRECOCE EVITANDO COMPLICAÇÕES
}

\author{
COELHO BHS
1 \\ brunohcoelho@gmail.com \\ ${ }^{1}$ Graduandos de Medicina da Universidade Federal do Rio Grande, Rio Grande - RS \\ 2Docente da Faculdade de Medicina da Universidade Federal do Rio Grande, Rio Grande - RS
}

Paciente masculino com 56 anos, vigilante, casado, residindo em Encruzilhada do Sul/RS. Em 10/03/2018, o paciente procurou o pronto atendimento (PA) por queda perda de força em membros inferiores (MMII). Há 30 dias, iniciou quadro de redução de força em membros superiores, evoluindo para MMII e queda. $\mathrm{O}$ acometimento motor progrediu em padrão ascendente, acompanhado de disfagia alta para sólidos. Negava parestesia, febre, dor, dispneia e quadro prévio de infecção. Hábitos fisiológicos mantidos. Paciente portador de diabetes, hipertensão e artrite gotosa em uso de metformina e enalapril. Afirmava tabagismo prévio e negava etilismo, uso de outras drogas e cirurgias. Ao exame físico, apresentava regular estado geral, mucosas úmidas e coradas, ventilando em ar ambiente. Auscultas e abdômen sem alterações. Pulsos periféricos palpáveis. Reflexos tendinosos profundos de MMII abolidos à direita e reduzidos à esquerda. Força muscular grau 3/5 em todos os membros. Após 2 dias no PA, foi internado em Unidade de Terapia Intensiva (UTI) sem necessidade de suporte ventilatório. Realizada punção lombar, apresentou LCR alterado (proteína: 72,2mg/dL; leucócitos: 2 células/campo; ausência de bactérias e antígeno criptocócico) e sorologias negativas para infecções sexualmente transmissíveis. Recebeu imunoglobulina intravenosa (IVIg) por 5 dias e, após 1 dia, seguiu à enfermaria em bom estado geral com melhora da força, fisioterapia para disfagia e gabapentina para tratamento da dor neuropática residual. As manifestações clínicas de paralisia ascendente simétrica aliadas à dissociação albumino-citológica do LCR possibilitaram o diagnóstico de Síndrome de Guillain-Barré - apesar de infrequentes os casos da doença na ausência de infecções prévias e exposições tóxicas - e evidenciaram o risco de progressão para insuficiência respiratória. Como medida preventiva, optou-se pela permanência em UTI. A IVIg se apresenta como terapia eficaz e preferível por sua praticidade. O diagnóstico precoce auxilia o bom prognóstico e melhora a qualidade de vida do paciente.

Descritores: Síndrome de Guillain-Barré; Diagnóstico Precoce; Complicações. 


\title{
"SOU UMA SANTIDADE": UM RELATO DE CASO DE ESQUIZOFRENIA
}

\author{
LAGO, PP1 , ZOLLNER, AMํ, SEIXAS, MC¹ KAÉ, TO², ZANATTA, LM². \\ pedro.p110@hotmail.com \\ ${ }^{1}$ Graduandos de Medicina da Universidade Federal do Rio Grande, Rio Grande - RS \\ ${ }^{2}$ Associação de Caridade Santa Casa do Rio Grande, Rio Grande - RS
}

Introdução: A esquizofrenia compreende uma categoria de transtornos psiquiátricos caracterizados, em geral, por distorções fundamentais e características do pensamento e da percepção e por afeto inadequado ou embotado. Objetivo: Este trabalho tem como objetivo discutir o diagnóstico e o tratamento dessa importante patologia psiquiátrica, bem como seu prognóstico, através de um relato de caso. Metodologia: Neste estudo, relatamos o caso de Lucas, 17 anos, que foi encaminhado pelo CAPSi ao plantão do Hospital Psiquiátrico da Santa Casa de Rio Grande em janeiro de 2018 por delírios místicos e de grandeza. Resultados: Ao chegar ao hospital, Lucas apresentava-se agitado, com fala confusa e relatando ter recebido a missão divina de "combater a malícia do mundo". Estava medicado com risperidona e biperideno, que, na dose inicial, não surtiram efeito sobre suas alterações de pensamento e comportamento - as quais vinham atrapalhando sua vida familiar e escolar e o fizeram receber o diagnóstico de esquizofrenia. O paciente fazia uso de maconha desde os 15 anos e seu pai e seu avô paterno também eram portadores de esquizofrenia. Lucas permaneceu internado por vinte e cinco dias, quando passou a apresentar bom entendimento de sua patologia e disposição para seguir tratamento ambulatorial, além de manifestar interesse em parar de fumar. Recebeu alta hospitalar com prescrição de 300mg diários de clozapina. Considerações finais: Com o presente relato, destacamos os efeitos da esquizofrenia sobre o convívio social e o funcionamento global do indivíduo, bem como seus possíveis fatores de risco - como o uso de maconha na adolescência - e bases biológicas, dentre elas, a hereditariedade.

Descritores: Esquizofrenia; Delírios; Alucinações. 
Vittalle - Revista de Ciências da Saúde v. 30, n. 2 (2018) 80-94

EDITORA E GRÁFICA DA FURG

CAMPUS CARREIROS

CEP 96203900

editora@furg.br 